\title{
THE APPLICATION OF BLOCKCHAIN TECHNOLOGY IN LOYALTY PROGRAMS
}

\author{
Valerio Stallone ${ }^{1,2}$, Anja Collenberg ${ }^{1}$, Andreas Rüedlinger ${ }^{1}$, Martin Wetzels $^{2}$ and Michael Klaas ${ }^{1}$ \\ ${ }^{I}$ ZHAW School of Management and Law, Center for Digital Marketing, Theaterstrasse 17, \\ CH-8401 Winterthur, Switzerland \\ ${ }^{2}$ Maastricht University, School of Business and Economics, Tongerstraat 53, NL-6211 Maastricht, The Netherlands
}

\begin{abstract}
This study investigated a digital app (loyalz), which enables users in Switzerland to collect, redeem, and share loyalty points offered by multiple merchants. The question of particular interest in this context was whether a new service (Swiss Loyalty Scheme), which will also enable the peer-to-peer (P2P) exchange of loyalty points between users, should be based on Blockchain technology (BCT), and whether this technology meets both the app users' and the merchants' requirements. A comparison of the different implementation possibilities of a BCT-based SLS solution with the qualitative survey results and the conditions the surveyed merchants have for the SLS that can be derived from these results shows that there is limited room for maneuver in the implementation or that due to this even the advantages of BCT disappear.
\end{abstract}

\section{KEYWORDS}

Blockchain, Loyalty Programs, Acceptance

\section{INTRODUCTION}

Between January 2019 and September 2019, the number of marketing technology companies based on the Blockchain increased worldwide from 80 to 250 (Epstein, 2019). Advocacy, loyalty, and referral applications promise to revolutionize approaches to increasing transparency and efficiency in operational customer relationship management (Epstein, 2019), especially in terms of cost efficiency, accuracy of accounting, and resulting data-driven decisions. Existing solutions do not meet companies' requirements, however, mainly owing to a lack of transparency (Wang, Luo, \& Xue, 2018). It has been suggested, therefore, that companies that already have a loyalty program should consider implementing a program based on crypto currencies (Shelper, Lowe, \& Kanhere, 2018).

For data protection reasons, the company with which the study was conducted is only mentioned anonymously as "loyalz". The loyalz App provides a digitalized version of the traditional stamp card offered by many stores, enabling customers to collect and redeem the loyalty points not only of one but all affiliated merchants. The company wants to develop a loyalty platform that also enables the P2P exchange of multi-brand loyalty points between users in real time: User A, who lives close to Merchant X, could thus collect loyalty points and, when visiting a district where Merchant $\mathrm{Y}$ is located, exchange these loyalty points with another user in order to redeem rewards there. loyalz would like to develop a solution it calls Swiss Loyalty Scheme (SLS). To make the new platform scalable, transparent, trustworthy, and audit-proof, the loyalz considers basing it on Blockchain technology (BCT).

We studied the possible acceptance and the feasibility of the SLS. In two different surveys, the views of stakeholders - the affiliated merchants and the users of the loyalz App - were collected to determine the conditions under which they would welcome the development of the SLS. This paper presents our findings and makes recommendations for the technical implementation of such a solution. 


\section{LOYALTY PROGRAMS \& BLOCKCHAIN}

In distributed ledger (DL) accounting, the use of BCT ensures that future transactions in a distributed system build on past transactions. Consistency and correctness are achieved by ensuring that a future transaction is only valid if it proves knowledge of all previous transactions and thus recognizes them as correct. A traditional accounting system, on the other hand, is managed by a single central office in which all stakeholders have confidence, not by several independent network participants, which only requires the confidence of the majority of participants. With the additional effort of multiple storage of the account book in the network and the cryptographic proof of correctness, a certain degree of independence and thus transparency, auditability, and scalability are achieved.

Loyalty programs (LPs) are incentive programs offered by merchants to reward customers for previous purchases and to motivate them to buy again. From retail outlets to specialty stores, most companies already have such a system in place. In B2B markets, loyal customers are traditionally treated better than those that buy in the marketplace (Lacey \& Morgan, 2009). Detailed program planning and incentive schemes must be put in place to retain selected target groups across the selected programs (Braun, Reinecke, \& Tomczak, 2017). According to representative studies, however, most memberships are inactive, and members rarely redeem their rewards (Kowalewski, McLaughlin, \& Hill, 2017; Heiniger, 2018). Wang, Luo, and Xue (2008) analyzed companies in the field of advocacy, loyalty, and referrals, such as Appsolutel, Bitrewards, Coupon Chain, Gatcoin, Incent, Loyalcoin, Loyyal, Qiibee, Sandblock, The Rouge Project and Tokenomy and also reviewed the literature on the topic. They identified three main entities of BCT-based LP design: the issuer, who owns the platform and distributes the loyalty points, the company (merchant), where the rewards are redeemed, and the customer (user), who redeems the rewards.

(A)

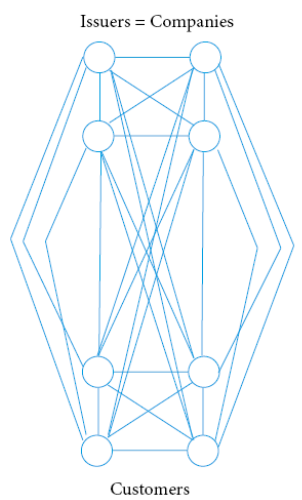

(B)

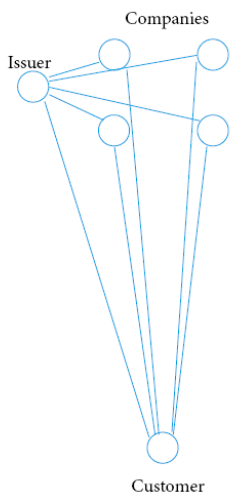

(C)

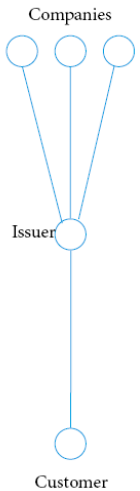

Figure 1. Entities in Blockchain-based loyalty programs

Figure 1 shows the three different LP designs for BCT. (A) represents a typical BCT adoption in loyalty programs that is trustworthy, $\mathrm{P} 2 \mathrm{P}$, and multi-brand: The absence of a central issuer is one of the main requirements emphasized in the literature (Shelper, Lowe, \& Kanhere, 2018; Wang, Luo, \& Xue, 2018). (B) is the version of an LP platform that still requires the issuer. In such cases, the issuer is represented either by a manufacturer or by a credit card payment provider (Bulbul and Ince, 2018; Choi, 2018; Napoli, 2018). (C) represents the existing LPs beyond the BCT world (Udegbe, 2017; Agrawal et al., 2018).

From a consumer's point of view, the use of BCT can lead to increased interaction with a brand because loyalty points can be redeemed more easily, which can lead to greater customer satisfaction: Customers store all their loyalty points in a single wallet and are awarded for their loyalty in real time (Kowalewski, McLaughlin , \& Hill, 2017; Burnett, 2018). A feature allowing users to trade points with other users will be an added benefit. 


\section{EMPIRICAL RESEARCH}

The aim of the empirical study was to conduct an acceptance analysis with regard to a multi-brand approach and the associated use of BCT. In the course of this analysis, merchants already in the loyalz portfolio as well as users of the loyalz App were interviewed regarding their acceptance of the proposed changes. In addition to the factors for the acceptance of a multi-brand approach, companies and users were asked about further characteristics in connection with the SLS, such as P2P.

\subsection{Methodology}

A two-stage procedure was chosen for the empirical examination of the research question. In a first step, a qualitative survey was carried out followed by a quantitative survey. To determine the relevant factors that can influence the acceptance of the SLS and of the P2P solution, qualitative interviews were first conducted with a small sample of subjects. For this purpose, five merchants were recruited from the loyalz portfolio. The 30-minute interviews were designed as guideline-based telephone interviews.

Following the qualitative interviews, particularly relevant topics were taken up and, based on a quantitative data collection with a larger sample consisting of merchants from the loyalz portfolio, a systematized and standardized online survey was conducted. In total, 71 data sets were available by the end of the survey period. Parallel to the survey of the merchants, users of the loyalz App were also interviewed about their perception of the concept of the SLS, again by means of a quantitative online survey. This survey focused on the acceptance of possible implementation variants. After completion of the data collection, a total of 128 data sets were available.

\subsection{Qualitative Data Collection}

The results from the qualitative interviews show that opinions regarding the introduction of the SLS are mixed. All the retailers who were surveyed agreed that the most important factors in the introduction of the SLS are transparency and traceability of billing. Other factors that were mentioned included the respectability of the dealers within the network and how easy the potential system would be to use. The P2P approach was seen as a customer advantage and less as an added value for merchants. The insights gained from the qualitative interviews were further investigated in the quantitative survey.

\subsection{Quantitative Data Collection}

As described above, the qualitative data collection consisted of a survey of affiliated merchants and a survey of app users. In the following, a descriptive overview of those samples is given. The majority of the surveyed businesses, about 63\%, have between 1-9 employees, about 20\% have about 10-49 employees, and only about $14 \%$ have more than 50 employees. Approximately half of the merchants surveyed serve fewer than 30 customers per day, about $30 \%$ serve between 30 and 100 customers, and $23 \%$ have more than 100 customers. The average revenue per sales transaction is below CHF 50 for about half of the companies. The percentage of customers using the loyalz App is less than $10 \%$ for more than $60 \%$ of the companies. It should be noted that most of the surveyed merchants are either active in the service segment or in the catering industry. About $12 \%$ of the merchants came from the retail or wellness sectors. A closer look at the sample of loyalz users shows that about $20 \%$ of the users belong to one of two age groups, 16-25 years or 26-35 years. The largest part, $34 \%$ of the surveyed users, is between 36-45 years old and about $20 \%$ are older than 46 years. In terms of income, $19 \%$ of the surveyed users earn less than CHF 4,000 per month, $38 \%$ have a monthly income of between CHF 4,000 and 8,000, and about 40\% earn more than CHF 8,000. As shown in Figure 3 below, the vast majority of the surveyed users use the loyalz App several times a month. Finally, the users were asked in how many stores they use the loyalz App. About 30\% use it in 1-2 stores, $48 \%$ use it in 3-5 stores, and about $20 \%$ in more than 6 stores. 


\section{RESULTS}

In the following sections, the results of the analysis of the acceptance of the SLS and of P2P by merchants and users are discussed. In addition, it is shown how the technical aspects of the solution described in the survey could play an essential role in the acceptance itself.

\subsection{Attractiveness of SLS}

Based on a short scenario described in a few sentences, the subjects were asked to rate the attractiveness of the SLS on a scale of 1 (very unattractive) to 6 (very attractive). With regard to this evaluation of the attractiveness, significant differences $(\mathrm{t}(93)=-8,849, \mathrm{p}=, 000)$ were found between merchants and users. While the users had a very positive attitude towards the SLS (MW=5.26, SD=1.12, $n=125$ ), the merchants were more critical $(\mathrm{MW}=3.20, \mathrm{SD}=1.70, \mathrm{n}=65)$. With an effect strength of $\mathrm{r}=0.67$, this corresponds to a strong effect according to Cohen (1998). The histogram in Figure 2 illustrates these differences graphically.

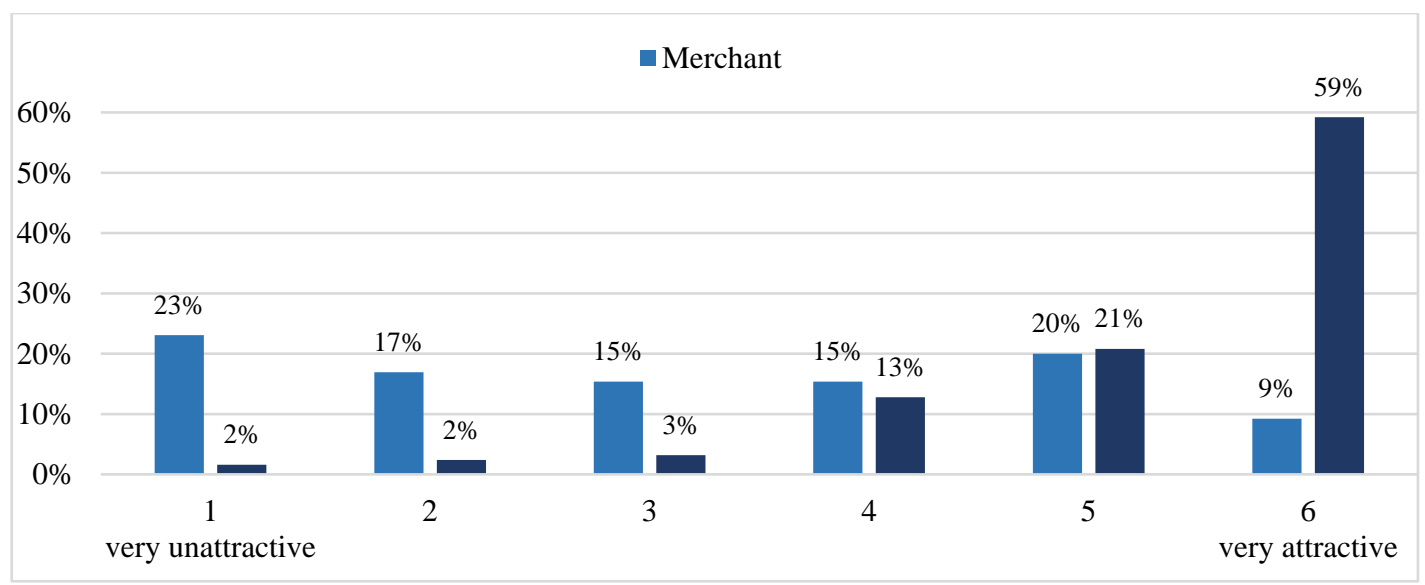

Figure 2. Attractiveness SLS ( $\mathrm{n}=190)$

Advantages of the proposed SLS as mentioned by the merchants included the possibility of winning new customers, the fulfillment of a customer need, as well as the possibility to profit from the loyalz network. The merchants saw the implementation of such a system as too complicated and, therefore, as a disadvantage. There were also concerns that the customers no longer would redeem the loyalty points from the merchant offering them. The surveyed users liked the flexibility of the system in terms of redeeming points and the fact that they would be able to try out new products or services.

\subsection{Attractiveness of P2P}

Both the affiliated merchants and the users of the loyalz App were asked how attractive they considered a $\mathrm{P} 2 \mathrm{P}$ approach on a scale from 1 (very unattractive) to 6 (very attractive). The attractiveness of a P2P solution was rated significantly higher $(\mathrm{t}(184)=-6,665, \mathrm{p}=, 000)$ by users $(\mathrm{MW}=4.86, \mathrm{SD}=1.37, \mathrm{n}=123)$ than by merchants $(\mathrm{MW}=3.21, \mathrm{SD}=1.99, \mathrm{n}=62)$.

\subsection{Technical Aspects of SLS and P2P}

In addition to answering questions concerning the acceptability of the SLS as well as of additional features, the merchants were also asked about aspects concerning the technical implementation of the SLS. Regarding the trust they would place in the loyalz as the operator of the SLS, the opinions of the merchants were divided. $21 \%$ of the merchants stated that they trusted the company completely, while $23 \%$ wanted to check the correctness of the data themselves. About one-quarter of the merchants stated that they trusted the loyalz 
as long as an independent authority was involved in controlling the system. However, a large proportion of merchants would not be willing to accept an increase in fees to pay for an independent control authority.

When asked how familiar they were with the term "BCT", $44 \%$ of the merchants stated that the term was unfamiliar to them. About one-third of the merchants stated that the term was somewhat familiar to them from the media, and about one-quarter thought that they understood the principles of BCT. Of those merchants who reported that they understood the technology in its basic principles, nine stated that they saw certain advantages in using BCT for a service such as the SLS. These advantages included the security of having a control authority that is cost-effective and supports abuse prevention.

Another point that was addressed in terms of the technical implementation of the SLS was the mapping of transactions. The merchants were asked to rate on a scale from 1 (not at all agree) to 6 (fully agree) whether they would be willing to purchase loyalty points from the loyalz in advance and then distribute them to their customers. As shown in Figure 3, this was not an option for these merchants (MW=2.19, $\mathrm{SD}=1.42, \mathrm{n}=63$ ). In addition, merchants were asked what effort they would be willing to invest to ensure the security of a transaction within the SLS. Here, too, the collected data show clear results. $64 \%$ of the merchants stated that the process of purchasing points must not become more complicated and that the existing system must be sufficient.

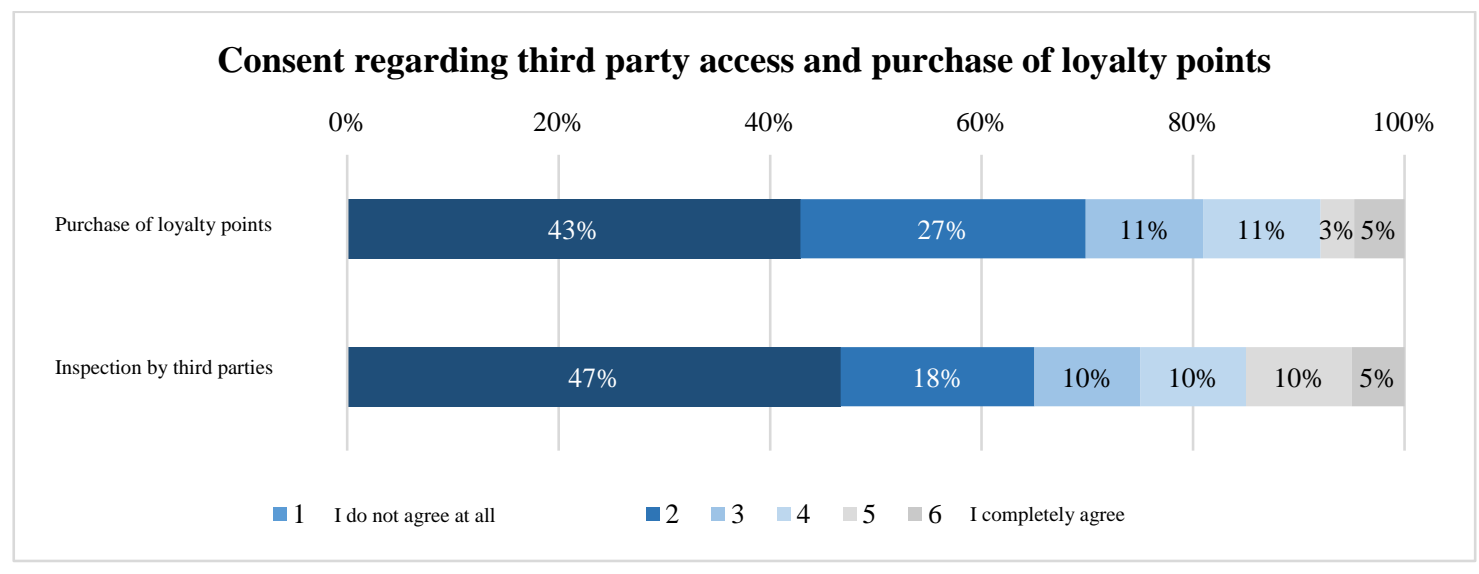

Figure 3. Consent regarding third-party access and the purchase of loyalty points $(60<\mathrm{n}<63)$

Merchants were also asked whether they would agree to allowing customers or third parties to see how many loyalty points a merchant was selling. Responses were again measured on a scale from 1 (I do not agree at all) to 6 (I completely agree). As shown in Figure 3, more than half of the merchants would not agree to such an option (MW=2.33, SD=1.61, $\mathrm{n}=60$ ). Regarding the question of whether an SLS must offer the possibility to evaluate a transaction in a detailed manner, $61 \%$ of the merchants were of the opinion that evaluations should be possible, but that the privacy of the user has a high priority.

\section{DISCUSSION}

As the collected data shows, a multi-brand approach would be particularly attractive from the users' point of view because it gives them more flexibility in redeeming loyalty points as well as the opportunity to try out new products or services. The merchants surveyed, on the other hand, are rather critical of such an approach and see major problems in its practical implementation. Possible reasons for the merchants' critical attitude could be that they use loyalz primarily for gaining new customers and increasing customer loyalty. In their eyes, the introduction of such a multi-brand approach would minimize the benefits of customer retention. In addition, many of the merchants expressed concerns about transparent billing.

The results of the data analysis show that from a user's perspective, the introduction of a $\mathrm{P} 2 \mathrm{P}$ program would be an attractive option. However, this option was rated as significantly less attractive by the merchants surveyed. Possible reasons for user approval are the greater flexibility that would result from the exchange of loyalty points among users. This is, however, where merchants see the danger: Recalling the example made earlier on, Merchant $\mathrm{Y}$ does not benefit if it allows a customer to redeem a reward earned with points from 
another merchant. In addition, merchants were found to be unwilling to "buy" loyalty points in advance. Finally, merchants are concerned about the cost of developing the new system: The potential introduction of a multi-brand approach would have to be as cost effective as possible. Only very few merchants would be willing to pay more to be affiliated with the SLS.

\subsection{Trustworthiness}

The most important advantage of implementing the SLS as a decentralized solution is that there is no need to trust the service operator loyalz, only the network operators. The trust issue encompasses the following types of trust, in particular (Shelper, Lowe, \& Kanhere, 2018):

- Manipulations: The trust of merchants that loyalz will not manipulate transactions out of self-interest (e.g., that no loyalty points are generated or deleted without justification).

- IT security: The trust that loyalz will operate the SLS in such a way that neither internal nor external attackers can manipulate the service in the long term. (For example, the service should be adequately secured against hacker attacks so that manipulations can be prevented or at least detected and reversed afterwards.)

- Privacy: The trust that loyalz will ensure that the data that it processes as operator is not misused and that it is adequately protected against access by third parties.

- Fair play: The trust by users that loyalz will continue to offer the service at fair conditions in the future and that customers will not be forced to make an expensive switch to another loyalty scheme.

According to the survey results, the trust merchants place in loyalz is extensive. Many of them fully trust loyalz as an intermediary and service provider. However, after the SLS is introduced, a large part of the merchants would also like to have either an independent control authority or the possibility to easily check the correctness of the data themselves.

\subsection{Transparency}

BCT-based services offer participants a high degree of transparency. All data for the validation of transactions and blocks are available to every network participant at any time. In many cases, the participants in the network are not anonymous, but pseudonymized at best (e.g., Bitcoin). While this mostly protects the system from manipulations, it also entails risks (Wang, Luo, \& Xue, 2018). For instance, third parties who gain knowledge of the pseudonyms can use big data analysis to obtain a whole range of information about the behavior and business activities of individual persons and companies. This can result in gross interference with the privacy of individuals or the business secrets of companies, which are no longer under the control of the service provider due to the public nature of the data. Complex techniques for concealing such information are used in some DL solutions. However, on the one hand, the traceability of the system suffers from this and, on the other hand, the smallest errors in these experimental protocols can lead to irrevocable, retroactive de-anonymization (Shelper, Lowe, \& Kanhere, 2018).

According to the survey, merchants agree that data concerning their business activities with the SLS must not be visible to others and would, therefore, have to be concealed in a DL. However, the merchants would like to have full transparency regarding the origin of "foreign" loyalty points that are redeemed and comprehensive evaluations of the transaction data. In order to address this dilemma, the concealment or pseudonymization of the data would have to be even more complex, so that both the anonymity of the stakeholders and the possibility of evaluation and verifiability are guaranteed. This technical balancing act involves security risks and can create additional dependencies. A cloud service with a database that is not publicly accessible can be protected more easily from unauthorized third parties. Anonymized or nonanonymized extracts of the data can be produced as required. In addition, parts of the data history that are no longer relevant can be moved to offline systems (for auditing purposes), so that they do not fall into the hands of attackers even if the active service systems are breached.

\subsection{Audit Safety}

Another advantage of a DL is the auditing security of the transactions. It could be argued that the cryptographic security mechanisms required for consensus in the network automatically provide this security. 
Therefore, a player with unlawful intentions cannot falsify past transactions or import new invalid transactions into the network. For the variant "real-time transactions", however, further cryptographic security mechanisms are necessary to ensure the authenticity and integrity of the real-time transactions in the DL. For such signatures and calculations, private key material is needed, which must be managed and protected with extreme care. In case such key material is compromised, an attacker can perform any action on behalf of the compromised user. In contrast to a traditional cloud solution, these actions cannot be undone in the DL (Wang, Luo, \& Xue, 2018). Furthermore, implementation errors in the cryptographic security mechanisms would have fatal consequences of a similar magnitude: Manipulations could probably not be undone or would not even be detected.

\subsection{Scalability}

The scalability of both a DL application and a cloud solution for the framework of the proposed SLS is no problem with today's technology and in both cases can be achieved cost-effectively (Wang, Luo, \& Xue, 2018). In connection with scalability, however, the expandability of a system must also be considered. Especially considering that most merchants are skeptical about a cross-company LS, the following questions arise:

Is it possible to start with a small proof-of-concept (PoC) system?

- Can additional players be easily added to the SLS at a later date as interest grows?

- Is it possible to dynamically define within the SLS subgroups what "peer-to-peer" transactions are allowed?

Additional merchants can be added without any problems and no adjustments to the running system are required. However, the restriction of certain loyalty points to subgroups of merchants is not possible in this case without introducing a "separate currency" for each subgroup (Wang, Luo, \& Xue, 2018).

In the implementation with real-time transactions, an extension of the accepted merchants requires an adjustment to the software (adding the permitted signature keys). Support for dynamic subgroups would also be conceivable in this scenario, but again requires significantly more complex developments and security checks than in a traditional cloud solution of a service such as the SLS.

\section{RECOMMENDATIONS}

A comparison of the different implementation possibilities of a BCT-based SLS solution with the qualitative survey results and the conditions the surveyed merchants have for the SLS that can be derived from these results shows that there is limited room for maneuver in the implementation or that due to this even the advantages of BCT disappear.

Starting from a traditional cloud service - such as the existing platform of the loyalz App - measures can be taken to increase the required transparency and authenticity, and thus ensure users' trust in the service. With a manageable effort, the SLS can be set up in a way that meets the identified requirements. To ensure the integrity of user interactions (e.g., generating and redeeming rewards), these can be provided with customer signatures in the database. Since only the respective customer is in possession of the private key, the service operator or external attackers cannot manipulate or forge user interactions. The service operator loyalz regularly signs and publishes the data stocks in an irrevocable manner. This publication of the data prevents subsequent manipulation of transactions and offers sufficient transparency for checks of the data by customers or third parties. The combination of both measures offers almost the same security as a BCT-based solution and can be used in both multi-brand and $\mathrm{P} 2 \mathrm{P}$ versions.

\section{CONCLUSION}

Loyalz wants to develop a loyalty platform (the SLS) that enables the exchange of loyalty points between different users in real time and, if possible, should be based on BCT to be scalable, transparent, trustworthy, and audit-proof. Our acceptance analysis revealed that certain aspects of the project are highly desirable from 
a user's perspective: The multi-brand approach and the points exchange feature should be pursued further. From a merchant's point of view, however, there is a need for more clarity. Whether the use of BCT will provide sufficient clarity was critically examined within the scope of a feasibility analysis. Several arguments were found that speak against the use of BCT and in favor of developing a solution with cloud service technology, which loyalz considers trustworthy. While the use of BCT was found to have potential, loyalz currently will not have the need to implement this technology to achieve their goals concerning the realization of their SLS.

\section{REFERENCES}

Agrawal, D. et al. (2018) 'Loyalty Points on the Blockchain', Business and Management Studies, 4(3). doi: $10.2139 / \mathrm{ssrn} .3246395$.

Braun, L., Reinecke, S. and Tomczak, T. (2017) Kundenbindung durch Loyalitätsprogramme. Available at: https://www.alexandria.unisg.ch/250550/1/BraunReineckeTomczak_Loyalitätsprogramme.pdf (Accessed: 4 April 2019).

Bulbul, S. and Ince, G. (2018) 'Blockchain-based Framework for Customer Loyalty Program', in 2018 3rd International Conference on Computer Science and Engineering (UBMK). IEEE, pp. 342-346. doi: 10.1109/UBMK.2018.8566642.

Burnett, S. (2018) Council Post: Can Blockchain Reinvigorate Loyalty Programs?, forbes.com. Available at: https://www.forbes.com/sites/forbesagencycouncil/2018/12/11/can-blockchain-reinvigorate-loyalty-programs/ (Accessed: 4 April 2019).

Choi, J. (2018) 'Modeling the Integrated Customer Loyalty Program on Blockchain Technology by Using Credit Card', International Journal on Future Revolution in Computer Science \& Communication Engineering, 4(2), pp. 388-391. Available at: http://www.ijfrcsce.org (Accessed: 23 June 2019).

Epstein, J. (2019) Blockchain Marketing Technology Landscape. Available at: https://www.neverstopmarketing.com/download/ (Accessed: 11 October 2019).

Heiniger, B. (2018) Cumulus \& Co. Family-Card: Warum Treuepunkte liegen bleiben - Handelszeitung, handelszeitung.ch. Available at: https://www.handelszeitung.ch/unternehmen/jeder-dritte-nutzt-seine-treuepunktenicht (Accessed: 7 July 2019).

Kowalewski, D., McLaughlin, J. and Hill, A. J. (2017) Blockchain Will Transform Customer Loyalty Programs, hbr.org. Available at: https://hbr.org/2017/03/blockchain-will-transform-customer-loyalty-programs (Accessed: 4 April 2019).

Lacey, R. and Morgan, R. M. (2009) 'Customer advocacy and the impact of B2B loyalty programs', Journal of Business \& Industrial Marketing, 24(1). doi: 10.1108/08858620910923658.

Napoli, F. (2018) L'impatto della tecnologia Blockchain nel marketing. Focus sui Customer Loyalty Program. Libera Università Internazionale degli Studi Sociali. Available at: https://tesi.luiss.it/22494/1/683471_NAPOLI_FLAMINIA_TESI_FLAMINIA_NAPOLI_683471.pdf (Accessed: 9 June 2019).

Shelper, P., Lowe, A. and Kanhere, S. S. (2018) 'Experiences from the Field: Unify Rewards - A Cryptocurrency Loyalty Prorgram', in Barahmand, S., Ghandeharizadeh, S., and Krishnamachari, B. (eds) Symposium on Foundations and Applications of Blockchain Proceedings.

Udegbe, S. E. (2017) 'Impact Of Blockchain Technology In Enhancing Customer Loyalty Programs In Airline Business', International Journal of Innovative Research and Advanced Studies (IJIRAS), 4(6). Available at: www.ijiras.com (Accessed: 4 December 2018).

Wang, L., Luo, X. and Xue, B. (2018) 'Too Good to Be True? Understanding How Blockchain Revolutionizes Loyalty Programs', in 24th Americas Conference on Information Systems, AMCIS 2018. Available at: https://aisel.aisnet.org/cgi/viewcontent.cgi?article=1298\&context=amcis2018 (Accessed: 4 December 2018). 